\title{
Optimization of Extraction Parameters of Polyphenols from Mango Seed Kernel through Response Surface Methodology
}

\author{
Junior Franck Ekorong Akouan Anta, Dorothée Marcelle Biloa, K. S. M. S. Raghavarao
}

\begin{abstract}
Phenolic compounds constitute an essential part of the human diet, and are of considerable interest due to their antioxidant properties. The traditional maceration method has been used for the extraction of polyphenols from mango seed kernel (Mangifera indica L.). Highlight the effects of different extraction parameters is useful to optimize the process, as well as to predict the extraction yield within the experimental domain with enough precision and confidence. The purpose of this work is to probe the influence of extraction time, extraction temperature and agitation speed on the extraction yield of phenolic compounds, and the total reducing power of the extract. The Surface Methodology (RSM), using the Doehlert design, have been applied. Optimal values of extraction yield and total reducing power was $36.99 \mathrm{mg}$ Gallic acid equivalent/g and $61.08 \mathrm{mg}$ Ascorbic Acid Equivalent/g respectively. The optimal conditions are 60 minutes of extraction time, $68.7^{\circ} \mathrm{C}$ extraction temperature and $424 \mathrm{rpm}$ for agitation speed. Under optimized conditions the experimental values well agreed with the values predicted by the model equations proposed.
\end{abstract}

Index Terms-Mango Seed Kernels, Phenolic Compounds, Total Reducing Power, Extraction Optimization, Response Surface Methodology.

\section{INTRODUCTION}

Oxidation is among the major factors of food deterioration during processing and storage [1]. Though the use of synthetic antioxidants, at legal limits, contribute to reduce rancidity and oxidative deterioration of foods, the metabolism, absorption and aggregation of these additives in the body carry a risk of toxicity [1], [2]. Since various plants, fruits in particular, prove to be important sources of natural antioxidants, particularly polyphenols, screening of edible plant materials for natural, harmless, effective and acceptable additives to enhance the shelf life of food products has long appeared as a valuable alternative. Still, obtaining antioxidants from plants has a relatively high cost, due particularly to the availability of fruits which are

Published on August 19, 2020.

J. F. A. A. Ekorong, Department of Environmental Technology, Food Technology, and molecular Biotechnology, Ghent University Global Campus, Incheon, South Korea; Faculty of Bioscience Engineering, Ghent University, Ghent, Belgium.

(ejfanta7@yahoo.fr)

D. M. Biloa, National Committee of Technology Development, Ministry of Scientific Research and Innovation, Yaoundé, Cameroon; Department of Food Science and Nutrition, National advanced School of AgroIndustrial Sciences, University of Ngaoundere, Ngaoundere, Cameroon. (biloamarcia @yahoo.fr)

K.S.M.S. Raghavarao, Food Engineering Department, Central Food Technical Research Institute, Mysore, India.

(raghavarao @ cftri.res.in) seasonal. In addition, extracting antioxidants from edible fruits may get in competition with the consumption use of the fruits. In general, non-edible parts of fruits, which are by-products of fruit processing, usually contain high level of polyphenols. This is the case of mango (Mangifera indica L.) peel and kernel which represent up to $17-22 \%$ of the fruit and is rich in polyphenols and saturated fatty acids [3] [5]. The mango kernel extract has shown to enhance oxidative stability of food products such as fresh type cheese and ghee [6], thus, prolonging their shelf life. In this respect, increasing interest in the use of mango kernels as a source of natural antioxidants and lipids is observed [7] for pharmaceutical, cosmetics and food uses.

Soxhlet extraction, maceration, microwave-assisted extraction, ultrasound-assisted extraction, high hydrostatic pressure extraction and supercritical fluid extraction with $\mathrm{CO}_{2}$ [8],[9] are among the different solvent extraction techniques used for extraction of phenolic compounds in plants. Each technique has its own advantages and disadvantages, but whatever the method, the main goal is the achievement of maximum extraction yield and avoidance of chemical modification of bioactive substances.

Therefore, the process needs optimized conditions for feasible extraction, which depends upon the nature of the sample [10]. Since the extraction yield is influenced by several factors such as the type and concentration of solvent, the solid-liquid (S/L) ratio, time, temperature, $\mathrm{pH}$, etc., both extraction speed and yield may be improved by choosing the best combination of process variables. In this respect, the response surface methodology (RSM), which is an all factors at the time approach, is more convenient. It also allows for possible interaction effects between variables to be taken into account. If adequately used, this powerful tool can provide the optimal conditions that improve a process [11], and predict which extraction conditions will produce a desired or optimum response [12] - [15].

Hence, the present work aimed at defining efficient and effective extraction conditions of polyphenols from mango seed kernels by maceration, taking into account, as influencing factors, the extraction time, the extraction temperature and the agitation speed, using experimental design with the RSM.

\section{MATERIALS AND MethodS}

\section{A. Source and preparation of mango kernels}

Mangoes were obtained from a local Indian mango processing unit. The pulp has been removed and the seeds collected. Their shell was manually removed carefully 
without scratching the kernel. The kernels were split vertically and dried through flow dryer, to obtain a moisture content less than $12 \%$ to avoid the growth of fungi. Dry kernels were crushed. Lipids were extracted by the Soxhlet method with Hexane for 10 hours. The defatted powder was ground and sieved again in order to obtain the desired particle size.

\section{B. Optimization of extraction by maceration with agitation speed}

\section{1) Experimental methodology}

The extraction parameters studied are the temperature, time and agitation speed. The solid/liquid (S/L) ratio, and the particle size, defined in preliminary studies, are 1/20 and $0.8 \mathrm{~mm}$ respectively. A three factors (Time, Temperature, and agitation speed) Doehlert design was built using the experience matrix presented in Table I.

TABLE I: THE ARRANGEMENT OF CHANNELS

\begin{tabular}{lllll}
\hline \hline $\begin{array}{l}\text { Standard } \\
\text { Order }\end{array}$ & Run & $\begin{array}{l}\text { Time } \\
(\mathrm{X} 1)\end{array}$ & $\begin{array}{l}\text { Temperature } \\
(\mathrm{X} 2)\end{array}$ & $\begin{array}{l}\text { Agitation speed } \\
(\mathrm{X} 3)\end{array}$ \\
\hline 1 & & 0 & 0 & 0 \\
2 & 3 & 0 & -1 & 0 \\
3 & 1 & 0 & 0 & 0 \\
4 & 4 & 1 & 1 & 0 \\
5 & 5 & 0 & 0 & 0 \\
6 & 2 & -1 & $-0,5$ & $-0,707$ \\
7 & 6 & $-0,5$ & $-0,5$ & $-0,707$ \\
8 & 8 & 0,5 & 0,5 & $-0,707$ \\
9 & 12 & $-0,5$ & 0,5 & $-0,707$ \\
10 & 14 & 0,5 & $-0,5$ & 0,7070 \\
11 & 7 & $-0,5$ & $-0,5$ & 0,7070 \\
12 & 9 & 0,5 & 0,5 & 0,7070 \\
13 & 13 & $-0,5$ & 0,5 & 0,7070 \\
14 & 15 & 0,5 & 0 & 0 \\
15 & 11 & 0 & 0 & 0 \\
16 & 10 & 0 & 0 & 0 \\
17 & 16 & 0 & 0 & 0 \\
\hline \hline
\end{tabular}

The experimental designs are presented in the form of matrices of dimensionless numbers, coded values, representing the different levels of a factor to be studied. This will facilitate the comparison of the effects of real variables, which are not always expressed in the same units. The implementation of a plan, then requires the calculation of the corresponding real values. The following formulas are used for that transformation [16]:

$x_{j}=\frac{U_{j}-U_{j}^{0}}{\triangle U_{j}}$

$U_{j}^{0}=\frac{U_{j}^{\max }+U_{j}^{\max }}{2}$

with: $x_{j}=$ value of the encoded variable $j ; U_{j}=$ value of the real variable $\mathrm{j} ; \mathrm{U}^{0} \mathrm{j}=$ value of the real variable $\mathrm{j}$ centrally at the centre of the domain, $\Delta \mathrm{U}_{\mathrm{j}}=$ the "step" variation, $\mathrm{U}_{\mathrm{j}}{ }^{\max }$ is the maximum value of the real variable $\mathrm{j} . \mathrm{U}_{\mathrm{j}}^{\mathrm{min}}$ is the minimum value of the real variable $j$. Table II presents the correspondence between reel and coded values.

Total phenolic compounds (TPC) extraction yield and total reducing power (TRP) were the responses followed.
TABLE II: CORRESPONDENCE BETWEEN REEL AND CODED VALUES

\begin{tabular}{llll}
\hline \hline Coded values & Time $(\mathrm{min})$ & Temperature $\left({ }^{\circ} \mathrm{C}\right)$ & Agitation speed $(\mathrm{rpm})$ \\
\hline-1 & 10 & 30 & -- \\
-0.707 & -- & -- & 100 \\
-0.5 & 22.5 & 45 & -- \\
0 & 35 & 60 & 350 \\
0.5 & 47.5 & 75 & -- \\
0.707 & -- & -- & 600 \\
1 & 60 & 90 & -- \\
\hline \hline
\end{tabular}

\section{2) Chemical analysis}

TPC was determined using the method described in [17], slightly modified. A mass of $0.5 \mathrm{~g}$ of sample was placed in a glass beaker and the appropriate volume of the solvent, methanol-acetone-water $(54: 23: 23)$ [18] was added to achieve the studied $\mathrm{S} / \mathrm{L}$ ratios. The content of the slurry was centrifuged for $10 \mathrm{~min}$, at $6000 \mathrm{xg}$ and $4{ }^{\circ} \mathrm{C}$. Two additional extraction cycle was undergone on the centrifugation residue and all the supernatants collected, pooled and stored at $4^{\circ} \mathrm{C}$. Aliquots of $20 \mu \mathrm{L}$ of this extract, are made up to $500 \mu \mathrm{L}$ with deionised water, and $250 \mu \mathrm{L}$ of a 10 times diluted Folin-Ciocalteau solution is added. To that mixture, $1.25 \mathrm{~mL}$ of sodium carbonate $(20 \% \mathrm{w} / \mathrm{v})$ are finally added. After incubation for $40 \mathrm{~min}$ at room temperature away from light, the reading was taken at $725 \mathrm{~nm}$. The total phenolic compounds content was expressed as an equivalent mass of Gallic acid (EGA) per gram of defatted mango seed kernel dry matter.

The TRP of the mango seed kernel extract was evaluated by the method described in [19]. The method is based on the reduction of Mo (VI) Mo (V) by compounds present in the extract in acidic condition. The reaction produces a green phosphate/molybdate complex, which optical density is recorded at $695 \mathrm{~nm}$, and the total reducing power is expressed as an equivalent mass of ascorbic acid (EAA) per gram of defatted dry matter.

Each analysis was completed in triplicate

\section{3) Statistical analysis}

The experimental design was generated and analysed by the MINITAB 16 software (Minitab, Ltd., Brandon Court, Unit E1-E2 Progress Way, Coventry, CV3 2TE, UK). Model validation was achieved by calculating [16], [20], [21]:

- the determination coefficient $\left(\mathrm{R}^{2}\right)$, related to the response variability;

- the adjusted $\mathrm{R}^{2}$, which gives a measure of the variation around the mean explained by the model [22];

- the Bias factor $\left(\mathrm{B}_{\mathrm{f}}\right)$ [Eq. 3] and the Accuracy factor $\left(\mathrm{A}_{\mathrm{f}}\right)$ [Eq. 4], which give the model precision;

- the average absolute deviation (AAD), which indicates the deviation of the model from the real values [Eq. 5]:

$\mathrm{B}_{\mathrm{f}}=10^{\frac{1}{\mathrm{n}} \sum_{\mathrm{i}=1}^{\mathrm{n}} \log \left(\frac{\mathrm{Y}_{\text {predicted }}}{\mathrm{Y}_{\text {observed }}}\right)}$

$\mathrm{A}_{\mathrm{f}}=10^{\frac{1}{\mathrm{n}} \sum_{\mathrm{i}=1}^{\mathrm{n}}\left|\log \left(\frac{\mathrm{Y}_{\text {predicted }}}{\mathrm{Y}_{\text {observed }}}\right)\right|}$ 
$A A D=\frac{\left[\sum_{i=1}^{p}\left(\frac{\left|y_{i, \text { observed }}-y_{i, p r e d i c t e d}\right|}{y_{i, \text { observed }}}\right)\right]}{n}$

For a perfect model, $\mathrm{R}^{2}=\mathrm{R}^{2}$ adj $=100 \%, \mathrm{AAD}=0$, and $\mathrm{B}_{\mathrm{f}}$ $=A_{f}=1$. However, a valid model should have $R^{2}$ adj $\geq 80 \%$ [23], $0<$ AAD $<0.3$ [24] and $0.75<\mathrm{B}_{\mathrm{f}} / \mathrm{A}_{\mathrm{f}}<1.25$ [25].

Graphic representations of the results were obtained through using Sigmaplot 12.5 (Systat Software Inc., 1735 Technology Drive, Suite 430, San Jose, CA 95110, USA).

\section{RESULTS AND DisCUSSIONS}

A. Modelling the combined effect of extraction factors on the extraction yield of polyphenols and total reducing power

Table 3 presents the responses obtained from experiments and predicted by models of the extraction yield of TPC and TRP, and the table 4 shows the results of the validation procedure. These values indicate that the responses tracked models are considered valid, which means that they follow and adequately explain the behaviour of each response within the field of study. These models are polynomial with first $(\mathrm{X} 1, \mathrm{X} 2, \mathrm{X} 3)$, second $\left(\mathrm{X} 1^{2}, \mathrm{X} 2^{2}, \mathrm{X} 3^{2}\right)$ and interactions $(\mathrm{X} 1 \mathrm{X} 2, \mathrm{X} 1 \mathrm{X} 3, \mathrm{X} 2 \mathrm{X} 3)$ components with the associated coefficients (Coef.). According to the value of the corresponding probability $(\mathrm{P})$, they are qualified as significant or not when $\mathrm{P} \leq 0.05$ or $\mathrm{P} \geq 0.05$ (Table $\mathrm{V}$ ).

\section{1) Extraction yield of total phenolic content (TPC)}

The model [Eq. 6], in coded variables, describe variations of extraction yield.

$C P T=32.80+2.74 \times X 1+3.81 \times X 2+2.07 \times X 3+$ $1.97 \times X 1^{2}-2.21 \times X 1 \times X 2-1.70 \times X 1 \times X 3-8.28 \times$ $X 2^{2}-1.42 \times X 2 \times X 3-6.72 \times X 3^{2}$

Quadratic effects of temperature $\left(\mathrm{X} 2^{2}\right)$ and agitation speed $\left(\mathrm{X}^{2}\right)$ were the most important contributions, tending to decrease the extraction yield (Table $\mathrm{V}$ ). Interaction between time and agitation speed $(\mathrm{X} 1 * \mathrm{X} 3)$ has the same tendency. This may be justified by the degradation of polyphenol extracts induced both by high temperature treatment and higher agitation speed, resulting from their temperature sensitivity. In fact, although high agitation speed increases the extraction yield, they generate a relative increase of the temperature of the medium, also exposing the polyphenols present in the extraction solvent to degradation risk. But the linear components of the model, the quadratic effect of time $\left(\mathrm{X}^{2}\right)$ contribute to the increase of extraction yield. This finding was expected, since these parameters are known to contribute to the increase of the extraction yield.

Fig. 1 illustrate the effect of two parameters at a time, on the extraction yield, the third parameter being always set at its optimal value obtained from the statistical analysis of results. Extraction time lower than $35 \mathrm{~min}$ shows no significant influence on polyphenols yield, despite a slight decline was observed. This may be explained by a temporary concentration balance of extracted component inside and outside of the diffusion matrix during extraction, and which would slow the release of the solute and thus reduce the extraction yield [26]. Beyond this value, there was an almost linear increase in extraction yield over time. This observation is consistent with the trend observed in the first step of this study. Temperature (X2) has an important impact. The bell shape allows identifying a phase of increase in extraction yield with increasing temperature up to $70^{\circ} \mathrm{C}$, and a reduction phase of the extraction yield above $70^{\circ} \mathrm{C}$, due to the heat sensitive nature of polyphenols. The steady increase in the extraction yield between $30^{\circ} \mathrm{C}$ and $70^{\circ} \mathrm{C}$ indicates that polyphenols from mango seed kernel have good stability at relatively high temperatures. Similar observations were made on China Litchi pericarp (Litchi chinensis Sonn.) [27], on the bark of the branches of black mulberry (Morus nigra L.) [28], on fresh table grapes from Algeria [29].

TABLE III: EXPERIMENTAL DESIGN RESPONSES FOR TOTAL PHENOLIC CONTENT AND TOTAL REDUCING POWER

\begin{tabular}{|c|c|c|c|c|}
\hline \multirow{3}{*}{$\begin{array}{l}\text { Std } \\
\text { Order }\end{array}$} & \multicolumn{4}{|c|}{ RESPONSES } \\
\hline & \multicolumn{2}{|c|}{$\begin{array}{l}\text { TPC (mg Gallic Acid } \\
\text { Equivalent/g) }\end{array}$} & \multicolumn{2}{|c|}{$\begin{array}{l}\text { TRP (mg Ascorbic Acid } \\
\text { Equivalent/g) }\end{array}$} \\
\hline & Observed & Predicted & Observed & Predicted \\
\hline 1 & $19.56 \pm 1.15$ & 20.58 & $36.93 \pm 1.78$ & 35.08 \\
\hline 2 & $32.76 \pm 1.29$ & 32.44 & $46.03 \pm 1.58$ & 43.90 \\
\hline 3 & $33.09 \pm 0.93$ & 32.80 & $41.60 \pm 1.41$ & 42.43 \\
\hline 4 & $36.80 \pm 1.63$ & 37.12 & $57.61 \pm 2.55$ & 59.74 \\
\hline 5 & $29.50 \pm 1.13$ & 28.48 & $40.10 \pm 0.88$ & 41.95 \\
\hline 6 & $21.08 \pm 1.23$ & 21.35 & $39.32 \pm 0.39$ & 41.64 \\
\hline 7 & $28.07 \pm 0.74$ & 27.11 & $39.69 \pm 1.34$ & 41.35 \\
\hline 8 & $27.08 \pm 1.35$ & 25.79 & $42.40 \pm 0.46$ & 41.93 \\
\hline 9 & $29.40 \pm 1.02$ & 29.35 & $45.66 \pm 1.17$ & 45.85 \\
\hline 10 & $32.58 \pm 1.69$ & 32.80 & $43.14 \pm 0.59$ & 42.43 \\
\hline 11 & $32.35 \pm 1.24$ & 32.80 & $41.60 \pm 1.15$ & 42.43 \\
\hline 12 & $27.45 \pm 0.88$ & 27.50 & $37.73 \pm 1.29$ & 37.54 \\
\hline 13 & $29.57 \pm 0.68$ & 30.86 & $40.80 \pm 1.73$ & 41.27 \\
\hline 14 & $28.97 \pm 0.95$ & 29.94 & $50.54 \pm 1.28$ & 48.88 \\
\hline 15 & $31.35 \pm 0.15$ & 31.09 & $59.13 \pm 2.44$ & 56.81 \\
\hline 16 & $33.42 \pm 1.16$ & 32.80 & $43.94 \pm 0.92$ & 42.43 \\
\hline 17 & $32.58 \pm 1.84$ & 32.80 & $41.85 \pm 1.03$ & 42.43 \\
\hline
\end{tabular}

TABLE IV: MODEL VALIDATION DATA

\begin{tabular}{llll}
\hline \hline $\begin{array}{l}\text { Validation } \\
\text { Parameters }\end{array}$ & $\begin{array}{l}\text { Extraction } \\
\text { yield (TPC) }\end{array}$ & $\begin{array}{l}\text { Total Reducing } \\
\text { Power (TRP) }\end{array}$ & Checking \\
\hline $\mathrm{R}^{2}$ & 91.49 & 84.30 & OK \\
Adjusted $\mathrm{R}^{2}$ & 89.3 & 80.85 & OK \\
$\mathrm{AAD}$ & 0.035 & 0.034 & OK \\
$\mathrm{B}_{\mathrm{f}}$ & 1.002 & 1.001 & $\mathrm{OK}$ \\
$\mathrm{A}_{\mathrm{f}}$ & 1.035 & 1.034 & $\mathrm{OK}$ \\
\hline Decision & Valid & Valid & \\
\hline \hline
\end{tabular}

TABLE V: ESTIMATED COEFFICIENT IMPACT AND CONTRIBUTION TO THE TOTAL PHENOLIC EXTRACTION YIELD AND TOTAL REDUCING POWER

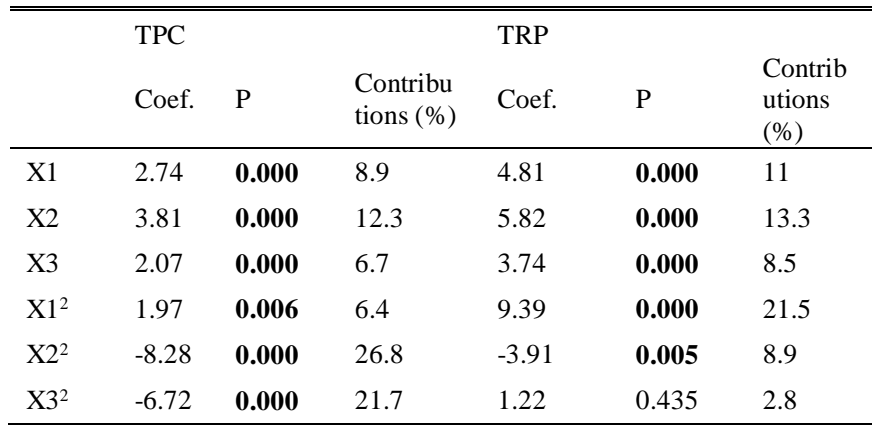




\begin{tabular}{lllllll}
\hline $\mathrm{X} 1 \mathrm{X} 2$ & -2.21 & 0.062 & 7.1 & 4.21 & 0.069 & 9.6 \\
$\mathrm{X} 1 \mathrm{X} 3$ & -1.70 & $\mathbf{0 . 0 4 3}$ & 5.5 & 2.84 & 0.082 & 6.5 \\
$\mathrm{X} 2 \mathrm{X} 3$ & -1.42 & 0.088 & 4.6 & 7.81 & $\mathbf{0 . 0 0 0}$ & 17.9 \\
\hline \hline
\end{tabular}
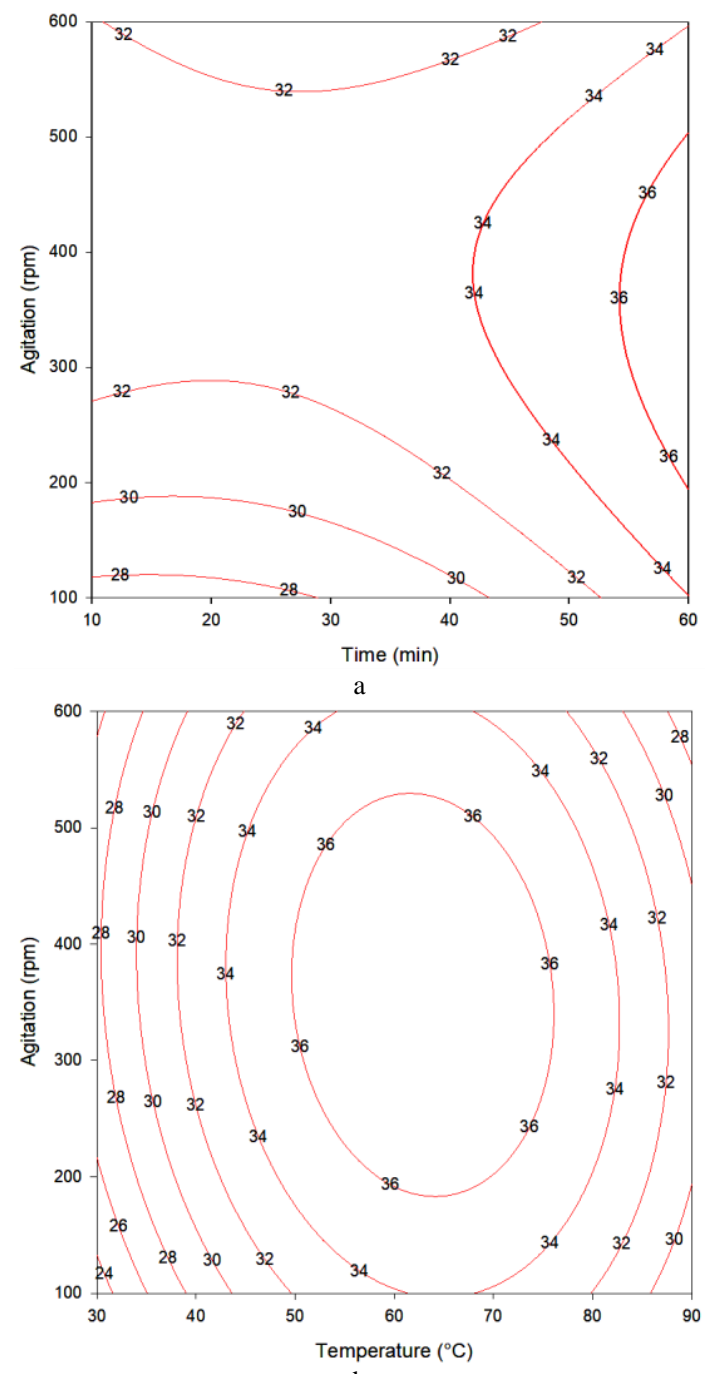

b

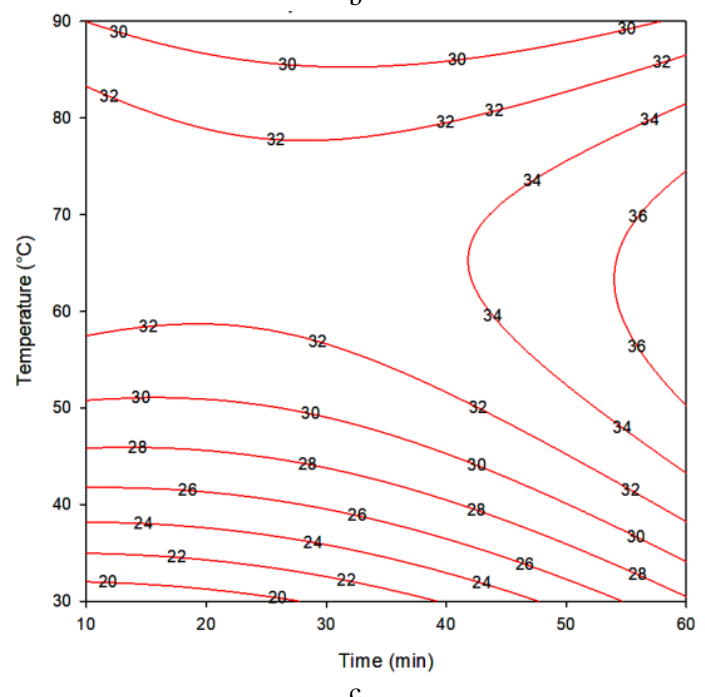

Fig. 1. Effect factors on extraction yield

Increase the agitation speed contributes to increase the extraction yield, but beyond 400-450 rpm, the extraction yield decreased. The observed increase in the extraction yield with increasing agitation speed is consistent with the mass transfer principle [30].
Extraction of polyphenols from mango seed kernel occurs by diffusion within the solid till the surface, and by convective mass transfer across the boundary layer at the interface of the solid with the solvent. Increasing the agitation speed allows to increase the effective contact between the particles and the solvent, thereby reducing the boundary layer surface of the particle. Similar observations were made by [31]. These researchers also stressed the mechanical action of agitation speed which would help accelerate the extraction of the active compounds from the particles and their dissolution. Beyond 400-450 rpm, the observed decrease in extraction yield may be due to the exposure, during high agitation speed, of polyphenols molecules to the effect of other factors, mainly temperature. It appears that the extraction yield is more sensitive to an increase in extraction time when the temperature is in a lower range. With the increase of temperature, the effect of time on extraction is less significant. Several authors have observed a similar behaviour [32], [33], [34]. Same observation can be made regarding the interaction between time and agitation speed, since increasing agitation speed reduces the impact of the extraction time. Moreover, at any given extraction time and agitation speed, an increase in the temperature significantly increased the extraction yield, but it decreased beyond $60-70^{\circ} \mathrm{C}$. In addition, an increase in temperature lowers the viscosity of the solvent which can thus more easily diffuse into the matrix, solubilise molecules and diffuse out. All this helped to increase the extraction yield by increasing the diffusion. In the same vein, the increase in temperature beyond the observed limit induces denaturation of the cell membrane, hydrolysis of polyphenols, reactions of polymerization and redox conditions which decrease their extraction yield [35].

\section{2) Total reducing power (TRP)}

The TRP is mainly linked to the type of antioxidant molecule and the overall concentration in the extract. Extraction parameters may also influence this property. The model equation obtained describing the variations in total reducing power at different extraction conditions is a second-degree type [Eq. 7].

$P R T=42.43+4.81 \times X 1+5.82 \times X 2+3.74 \times X 3+$ $9.39 \times X 1^{2}+4.21 \times X 1 \times X 2+2.84 \times X 1 \times X 3-3.91 \times$ $X 2^{2}+7.81 \times X 2 \times X 3+1.22 \times X 3^{2}$

All the linear components (X1, X2, X3), as well as the quadratic elements of time and temperature $\left(\mathrm{X} 1^{2}, \mathrm{X} 2^{2}\right)$, and the interaction between temperature and agitation speed (X2X3) have a significant effect on the TRP (Table V). All extraction parameters and their interactions contributed to the increase in total reducing power, except the quadratic effect of temperature $\left(\mathrm{X}^{2}\right)$. This finding is coherent with previous observation above, since all factors contribute to increasing the quantity of polyphenols extracted into the solvent, while high temperatures degrade the polyphenols in the extract.

Based on the overall effects of the interactions between factors on the reducing power of total polyphenols extracted, the increase in extraction time contributed to improve the total reducing power. In general, the antioxidant power is proportional to the quantity of polyphenols extracted. It is 
therefore understandable that the antioxidant power increases with increasing extraction yield [36] - [39].

Despite the decrease in extraction yield with temperatures above $70{ }^{\circ} \mathrm{C}$ (Fig. 2a, b \& c), the antioxidant activity does not drop but increase. This may be due to increase of the antioxidant property by gentle pyrolysis caused by high temperature [40], [41].

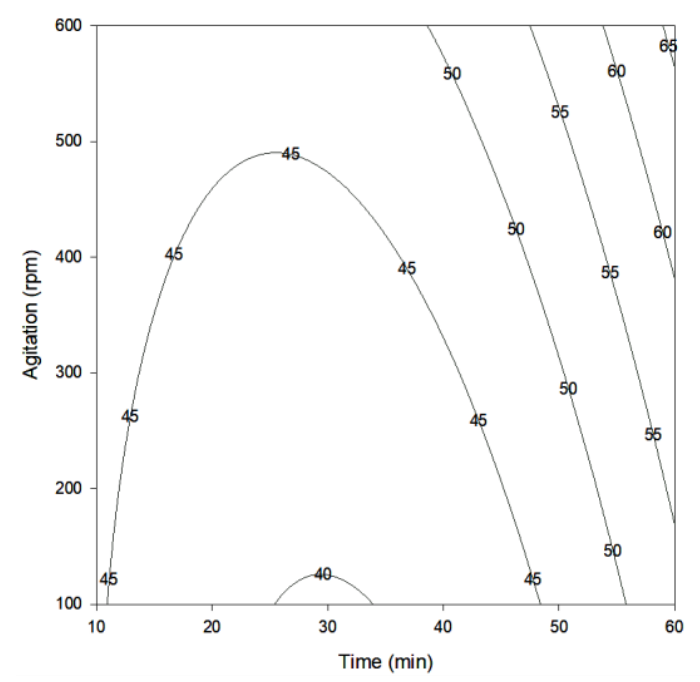

a

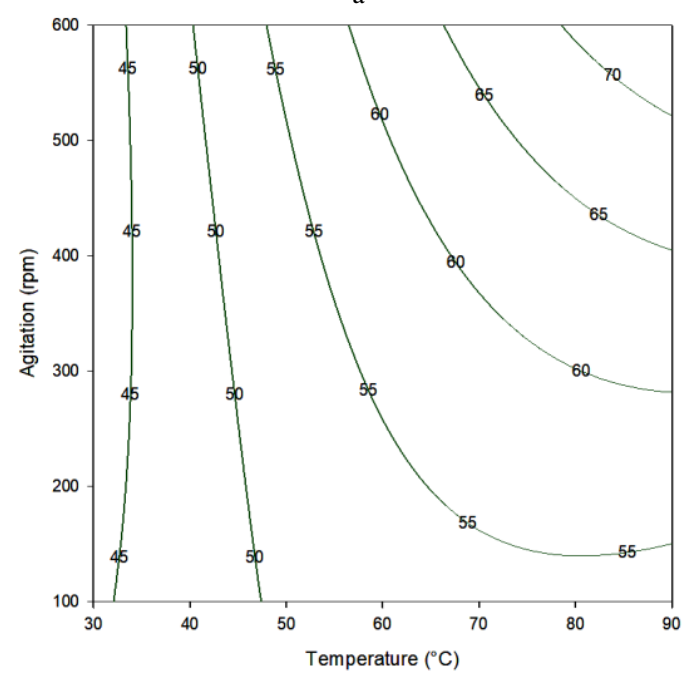

$\mathrm{b}$

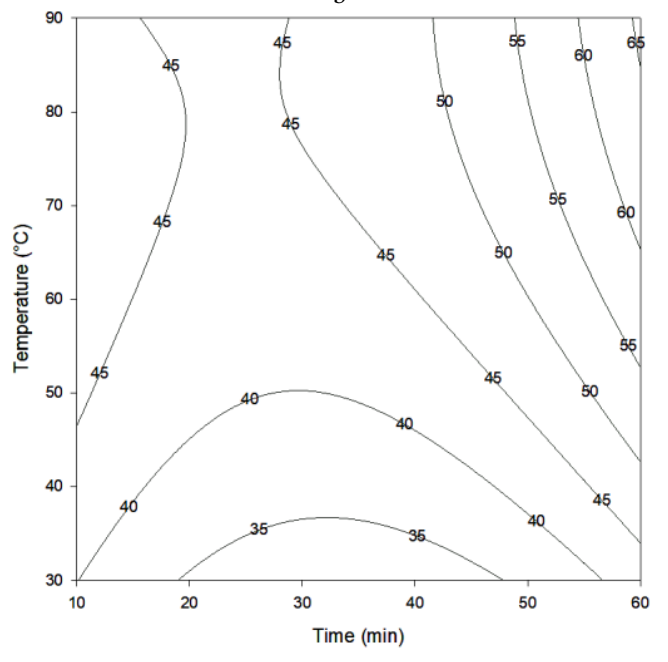

Fig. 2. Effect of interactions between factors on total reducing power

The interaction between time and temperature, and between time and agitation speed follows the same trend for the quantity of polyphenols extracted, coupled with the temperature activation effect. Fig. 2c, showing the interaction between temperature and agitation speed, unveils the importance of these factors because the lowest values of experimental parameters cause a relatively high reducing power compared to other interactions. The agitation speed contributes to the increase of the extraction yield.

3) Optimizing extraction of total polyphenols

The objective of this work was to determine the best conditions for maximum extraction of TPC from mango seed kernels with high TRP. It was therefore necessary to do a multi response optimization which allows to find the best compromise to achieve the objectives for several factors at once. Table VI presents the results of the multi response optimization.

TABLE VI: OPTIMAL CONDITIONS FOR EXTRACTION OF TOTAL POLYPHENOLIC COMPOUNDS

\begin{tabular}{lllll}
\hline \hline & & Time $(\mathrm{min})$ & $\begin{array}{l}\text { Temperature } \\
\left({ }^{\circ} \mathrm{C}\right)\end{array}$ & $\begin{array}{l}\text { Agitation } \\
(\mathrm{rpm})\end{array}$ \\
\hline \multirow{2}{*}{$\begin{array}{l}\text { Optimal } \\
\text { conditions }\end{array}$} & Coded & 1 & 0.289 & 0.208 \\
& Reals & 60 & 68.7 & 424 \\
& Implemented & 60 & 68.7 & 420 \\
\hline \hline \multirow{5}{*}{ Responses } & TPC & Predicted: $36.99 \mathrm{mg} \mathrm{EGA} / \mathrm{g}$ & \\
& & Observed: $37.8 \pm 0.57 \mathrm{mg}$ EGA/g & \\
& & Fisher t Test: $\mathrm{P}=0.271$ & \\
& & Predicted: $61.08 \mathrm{mg}$ EAA/g & Observed: $59.4 \pm 1.28 \mathrm{mg}$ EAA/g & 0.961 \\
\hline
\end{tabular}

For reasons of reproducibility of the optimum value of the agitation speed, the nearest agitation speed was used and the results were compared to those predicted by the model equation at optimal conditions, using the Fischer t test. The results showed no significant differences $(P=0.05)$. This result also validates the model by experimental implementation. Composite desirability shows that it is relatively easy to obtain extract rich in polyphenols, which have strong antioxidant activity.

The variation of extraction yield according to the number of extraction cycles at optimal conditions is presented in Fig. 3. The first extraction cycle provided more than $80 \%$ of the quantity of polyphenols extracted by the 3 cycles, and cumulatively with the 2 nd cycle, it goes up to more than $95 \%$. The great difference in extraction yields between cycles indicates a great extraction ability at the defined conditions. These results show that, although in the defined optimal conditions, 2 extraction cycles are enough.

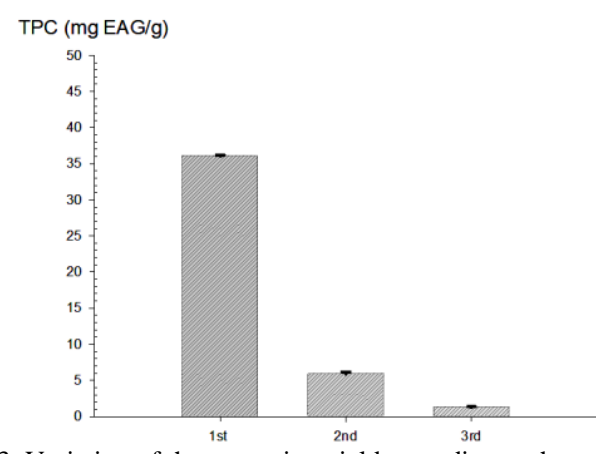

Fig. 3. Variation of the extraction yield according to the number of extraction cycles. 


\section{CONCLUSION}

An effective maceration technique for extracting polyphenols from mango seed kernel was optimized. The optimization was mainly focused on the polyphenol extraction yield and the total reducing power of the extract. All the studied factors show significant effect on the extraction yield and total reducing power, but present some limitation because of the sensitive nature of the polyphenols and the possible interaction with other extracted compounds. The optimal combination of factors is: 60 minutes' extraction time, $68.7^{\circ} \mathrm{C}$ extraction temperature and $424 \mathrm{rpm}$ agitation speed, with an optimal yield of $36,99 \mathrm{mg}$ EAG/g and $61,08 \mathrm{mg} \mathrm{EAA} / \mathrm{g}$ for the total reducing power. The application of this combination allows extracting a great quantity of polyphenols. However, after 3 extraction cycles, it doesn't seem to reach the maximum extractable quantity of polyphenolic compounds. This suggests the use of an advanced technique to achieve the maximum extraction in a shorter time.

\section{ACKNOWLEDGEMENTS}

This work was performed in the Central Food Technical Research Institute (CFTRI), Mysore, with the support of the TWAS-CSIR Postgraduate Fellowship.

\section{REFERENCES}

[1] N. K. Prasad, S. Divakar, G. R. Shivamurthy, S. M. Aradhya, 'Isolation of a free radical-scavenging antioxidant from water spinach (Ipomea aquatica Forsk)' J. Sci. Food Agric., 85, pp. 1461-1468, 2005.

[2] R. C. Linderschmidt, A. F. Tryka, M E. Goad, H. P. Witschi, 'The effects of dietary butylated hydroxytoluene on liver and colon tumor development in mice', Toxicology, 38, pp 151-160, 1986.

[3] D. Puravankara, V. Bohgra, R. S. Sharma, 'Effect of antioxidant principles isolated from mango (Mangifera indica L.) seed kernels on oxidative stability of buffalo ghee (butter-fat)', J. Sci. Food Agric., 80 , pp 522-526, 2000.

[4] A. J. Núñez-Sellés, 'Antioxidant therapy: myth or reality?', J. Braz. Chem. Soc., 16 (4), pp 699-710, 2005.

[5] S. Kittiphoom, 'Utilization of Mango seed', Int. Food Res. J., 19 (4), pp 1325-1335, 2012.

[6] S. S. Parmar, R.S. Sharma, 'Effect of mango (Mangifera indica L.) seed kernels pre-extract on the oxidative stability of ghee', Food Chem., 35, pp 99-107, 1990.

[7] S. S. Arogba, 'Mango (Mangifera indica) kernel: Chromatographic analysis of the tannin and stability of the associated polyphenol oxidase activity', J. Food Comp. Anal., 13, pp 149-156, 1990.

[8] F. Dahmoune, G. Spigno, K. Moussia, H. Remini, A. Cherbal, K. Madani, 'Pistacia lentiscus leaves as a source of phenolic compounds: Microwave-assisted extraction optimized and compared with ultrasound-assisted and conventional solvent extraction', Ind Crop. Prod., 61, pp 31-40, 2014.

[9] A. Khoddami, M. A. Wilkes, T. H. Roberts, 'Techniques for analysis of plant phenolic compounds', Molecules, 18, pp 2328-2375, 2013.

[10] C. Santos-Buelga, S. Gonzalez-Manzano, M. Dueñas, A. M. Gonzalez-Paramas, 'Extraction and isolation of phenolic compounds', Methods Mol. Biol., 864, pp 427-464, 2012.

[11] P. D. Haaland, 'Experimental Design in Biotechnology', New York, Marcel Dekker, 1989.

[12] G. E. P. Box, W. G. Hunter, and J. S Hunter, 'Statistics for Experimenters: an introduction to design, data analysis, and model building', New York, John Wiley; 1978.

[13] R. H. Myers, D. C. Montgomery, 'Response surface methodology, process and product optimization using designed experiments', 2nd Ed. New York: John Wiley and Sons; 1995

[14] M. H. Canteri-Schemin, H. C. R. Fertonani, N. Waszczynskyj, G. Wosiacki, 'Extraction of pectin from apple pomace', Braz. Arch. Biol. Technol., 48 (2), pp 259-266, 2005.
[15] L. A. L. Soares, G. G. Ortega, P. R. Petrovick, P. C Schmidt 'Optimization of Tablets Containing a High Dose of Spray-Dried Plant Extract: A Technical Note', AAPS PharmSciTech, 6 (3), pp 368-371, 2005.

[16] Desobgo Z.S.C., Nso E.J., Tenin D., Kayem G.J. Modelling and optimizing of mashing enzymes-effect on yield of filtspeed of unmalted sorghum by use of response surface methodology. Journal of the Institute of Brewing. 2010; 116: 62-69

[17] H. P. S. Makkar, M. Blummel, N. K. Borowy, K. Becker, 'Gravimetric determination of tannins and their correlations with chemical and protein precipitation methods', J. Sci. Food Agric., 61, pp 161-165, 1993.

[18] J. F. A. A. Ekorong, P.-D. Mbougueng, E. Durand, B. Barea, P. Villeneuve, R. Ndjouenkeu, 'Model development to enhance the solvent extraction of polyphenol from mango seed kernel', Journal of biologically active products from nature, 8 (1), pp 51-63, 2018.

[19] P. Prieto, M. Pineda, M. Aguilar, 'Spectrophotometric quantitation of antioxidant capacity through the formation of phosphomolybdenum complex: specific application to determination of vitamin E', Anal. Biochem., 269, pp 337-341, 1999.

[20] J. F. A. A. Ekorong, G. Zomegni, S. C. Z. Desobgo, R. Ndjouenkeu, 'Optimization of drying parameters for mango seed kernels using central composite design', Bioresources and Bioprocessing, 2, 8, 2015.

[21] P. A. N. Kouteu, Y. Jiokap - Nono, C. Kapseu, 'Pre-treatment of cassava stems and peelings by thermohydrolysis to enhance hydrolysis yield of cellulose in bioethanol production process', Renew. Energy, 97, pp 252-265, 2016.

[22] B. S. Baboukani, M. Vossoughi, I. Alemzadeh, 'Optimisation of dilute-acid pretreatment conditions for enhancement sugar recovery and enzymatic hydrolysis of wheat straw', Biosystems engineering, 111, pp 166-174, 2012

[23] A. M. Joglekar, A. T. May, 'Product excellence through design of experiments', Cereal Food. World., 32, pp 857-868, 1987.

[24] D. Bas, I. H. Boyac, 'Modeling and optimizing I: Usability of response surface methodology', J. Food Eng., 78, pp 836-845, 2007.

[25] P. Dalgaard, L. V. Jorgensen, 'Predicted and observed growth of Listeria monocytogenes in seafood challenge tests and in naturally contaminated cold-smoked salmon', Int. J. Food Microbiol., 40, pp $105-115,1998$

[26] E. M. Silva, J. N. S. Souza, H. Rogez, J. F. Rees, Y. Larondelle, 'Antioxidant activities and polyphenolic contents of fifteen selected plant species from the Amazonian region', Food Chem., 101, pp 1012-1018, 2007.

[27] N. Ruenroengklin, J. Zhong, X. Duan, B. Yang, J. Li, Y. Jiang, 'Effects of various temperatures and $\mathrm{pH}$ values on the extraction yield of phenolics from Litchi fruit pericarp tissue and the antioxidant activity of the extracted anthocyanins', Int. J. Mol. Sci., 9, 1333-1341, 2008.

[28] C. Wu, L. Xu, J. C. Liu, X. Z. Huang, Y. M. Maimaiti, 'Process optimization for total polyphenol extraction from the tree branch bark of Xinjiang black mulberry (Morus nigra L.) by response surface methodology', Food Sci., 32, pp 104-107, 2011.

[29] F. Benmeziane, R. Djamai, Y. Cadot, R. Seridi, 'Optimization of extraction parameters of phenolic compounds from Algerian fresh table grapes (Vitis vinifera)', Int. Food Res. J., 21, 3, pp 1061-1065, 2014.

[30] D. Tagliazucchi, E. Verzelloni, D. Bertolini, A. Conte, 'In vitro bioaccessibility and antioxidant activity of grape polyphenols', Food Chem., 120, 2, pp 599-606, 2010.

[31] C. H. Chan, R. Yusoff, G. C. Ngoh, F. W. Kung, 'Microwave-assisted extractions of active ingredients from plants', J. Chromatogr. A. 1218, pp 6213-6225, 2011

[32] X. Wang, Y. Wu, G. Chen, W. Yue, Q. Liang, Q. Wu, 'Optimisation of ultrasound assisted extraction of phenolic compounds from Sparganii rhizoma with response surface methodology', Ultrason. Sonochem., 20, pp 846-854, 2013.

[33] M. T. Escribano-Bailon, C. Santos-Buelga, 'Polyphenol extraction from foods', In Methods in Polyphenol Analysis, Royal Society of Chemistry, London, ed. G. Santos-Buelga, C. Williamson, 2003. pp. $1-16$.

[34] V. Bharathi, J. Patterson, R. Rajendiran, 'Optimization of Extraction of Phenolic Compounds from Avicennia marina (Forssk.) Vierh using Response Surface Methodology', Int. J. Biol. Biomol. Agric. Food Biotechnol. Eng., 5, 8, pp 483-487, 2011.

[35] B. Abad-Garcia, L. A. Berrueta, D. M. L. Marquez, I. C. Ferrer, B. Gallo, F. Vicente, 'Optimization and validation of methodology based on solvent extraction and liquid chromatography for the simultaneous determination of several polyphenolic families in fruit juices', J. Chromatogr. A., 1154, 87-96, 2007. 
[36] P. Budrat, A. Shotipruk, 'Enhanced recovery of phenolic compounds from bitter melon (Momordica charantia) by subcritical water extraction', Sep. Purif. Technol., 66, pp 125-129,2009.

[37] C. Lopez-Alarcon, A. Aspée, E. Lissi, 'Antioxidant reactivity' evaluated by competitive kinetics: influence of the target molecule concentration', Food Chem., 104, pp 1430-1435, 2007.

[38] M. Hassas-Roudsari, P. R. Chang, R. B. Pegg, R. T. Tyler, 'Antioxidant capacity of bioactives extracted from canola meal by subcritical water, ethanolic and hot water extraction', Food Chem., 114, pp 717-726 2009.

[39] J. R. Vergara-Salinas, J. Perez-Jiménez, J. L. Torres, E. Agosin, J. R. Perez-Correa, 'Effects of Temperature and Time on Polyphenolic Content and Antioxidant Activity in the Pressurized Hot Water Extraction of Deodorized Thyme (Thymus vulgaris)', J. Agric. Food Chem., 60, pp 10920-10929, 2012.

[40] Y. Wang, C.-T. Ho, 'Polyphenolic Chemistry of Tea and Coffee: A Century of Progress', J. Agric. Food Chem., 57, pp 8109-8114, 2009.

[41] N. Nićiforović, H. Abramovich, 'Sinapic Acid and Its Derivatives: Natural Sources and Bioactivity', Comprehensive Reviews in Food Science and Food Safety, 13, 1, pp 34-51, 2014.

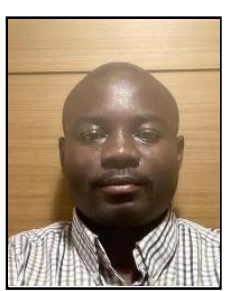

Ekorong Akouan Anta Junior Franck, Agro-food process Engineer (MSc Eng) since 2011, MSc in Food Process Engineering since 2012. Actually, Research Assistant at Department of Environmental Technology, Food Technology, and molecular Biotechnology, Ghent University Global Campus, Incheon, South Korea.

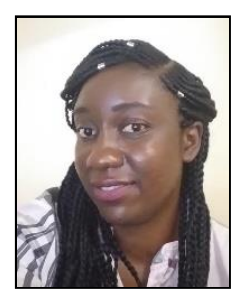

Biloa Dorothée Marcelle, Agro-food process Engineer (MSc Eng) since 2011, MSc in Food Process Engineering since 2012. Actually, Research Assistant at the National Committee of Technology Development, Ministry of Scientific Research and Innovation, Yaoundé, Cameroon.

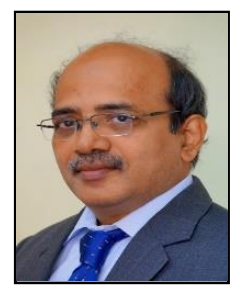

KSMS Raghavarao, Chief Scientist, Ph. D holder since 1987. Actually, acting Director of the CSIR CFTRI, Mysore, India 